\title{
Piloting the eBig3 A Triple-screen e-Learning Approach
}

\author{
Atis Kapenieks ${ }^{1}$, Bruno Zuga ${ }^{1}$, Ieva Vitolina ${ }^{1}$, Janis Kapenieks jr. ${ }^{1}$, Aleksandrs Gorbunovs ${ }^{1}$, \\ Merija Jirgensons ${ }^{1}$, Janis Kapenieks sr. ${ }^{1}$, Ieva Kudiña ${ }^{1}$, Kristaps Kapenieks ${ }^{1}$, \\ Rudolfs Gulbis ${ }^{1}$ and Antra Balode ${ }^{2}$ \\ ${ }^{I}$ Distance Education Study Centre, Riga Technical University, Azenes Iela 12, Riga, Latvia \\ ${ }^{2}$ Latvia University of Agriculture, Jelgava, Latvia \\ \{atis.kapenieks, bruno.zuga, ieva.vitolina, janis.kapenieks_1, aleksandrs.gorbunovs, merija.jirgensons, \\ janis.kapenieks, ieva.kudina, kristaps.kapenieks, rudolfs.gulbis\}@rtu.lv, antra.balode@llu.lv
}

Keywords: e-Learning, t-Learning, m-Learning, eBig3 Learning.

Abstract: In this report / study we present our recent progress on multi-screen e-learning development entitled eBig3. It is a new approach to technology supported education encouraging involvement in lifelong learning education. The approach effectively integrates the popular technologies of television, Internet, and mobile phones Here we present the results of ten course pilots offered in 2013 with the eBig3 media formats. The target group for the courses was the general public. And the three-pronged approach worked; the response showed a radical increase of registration for eBig3 courses compared to traditional registration for online courses. The course delivery formats were also more successful than blended learning formats. Our results showed that the new approach significantly increased the availability of eCourses and that users felt encouraged to stay the duration of the course. Moreover, the results indicated that the approach helped to close the gap between expectations and actual achievements for life-long-learning in general.

\section{INTRODUCTION}

Each big breakthrough in education technology has announced and encouraged the creation of a new type of learning (Pfeffer, 2012). TV-education was inspired by the large scale penetration of television into people's homes; m-learning developed together with smart phones (Ducey and Phalen, 2011), (ITUD, 2010), (ITU-D, 2009), (ITU, 2008), (Google, 2012), (Zaller, 2013), (Turrill, 2013), (Byers, 2013). E-learning initially was regarded as a Personal Computer technology for education. Nowadays we usually refer to all digital education technologies as learning. The new twist and challenge is when learners are using all three technologies to suit their style and convenience. Developers, however, design separate approaches for each of the big three learning technologies: e-learning, m-learning and tlearning. To meet the challenge of applying all three technologies at the same time and adjusting them to the habits of users, we designed an approach that was user sensitive and functioned with the three approaches simultaneously. The eBig3 pilot incorporates these adjustments and forges a new path for technological learning (Kapenieks et al., 2012b).

With the eBig3 approach, we assign complimentary applications for TV, Internet, and mobile phone to ensure high quality user-friendly learning. eBig3 has the capacity to respond to the skills/habits of a large target group of users that spans all age groups of life-long learners. eBig3 learning tends to reach, deliver content, and learning support to a diverse group of users; nor does it require continuous upgrade of technology and special skills (Kapenieks et al., 2012c).

The project has been carried out in a cross-border region of Latvia and Lithuania and included universities from both nations. The target group for the eBig3 courses was the general public. This paper reports on the Latvian results. At the beginning of the project researchers have used "Enterprise Knowledge Development (EKD) method to capture and systematize the experts' and stakeholders' knowledge about various learning approaches and content delivery technologies. Each of three selected technologies (computer, internet, mobile, and television were tested for material qualities and 
interaction capacity to determine which was the most suitable for each function. Then the Technologies were combined to be responsive to the widest possible audiences. We achieved audience interest and engagement by: a) exhibiting entertaining videos clips on $\mathrm{TV}$, each lasting about 12 minutes; one of more such video clip had been prepared for each course; b) ensuring a smooth registration process and providing regular organisational and context dependant learning support over the SMS messaging service; c) making full instructional material available in an online learning environment. After initial review of the outcomes and formulating the first eBig3 model we designed the prototype for the eBig3 course (Kapenieks et al., 2012a).

\section{2 eBig3 COURSE PROTOTYPE}

The eBig3 three course prototype consists of three learning contents formulated to fit each media type: t-content, e-content, and m-content. We modelled the t-content on the Discovery documentaries. We designed an engaging video on course topics and exhibited it on TV. This video is as interesting to watch as a traditional TV movie. At the bottom of the film appears a banner inviting the public to join the course with complete registration details provided (Figure 1).

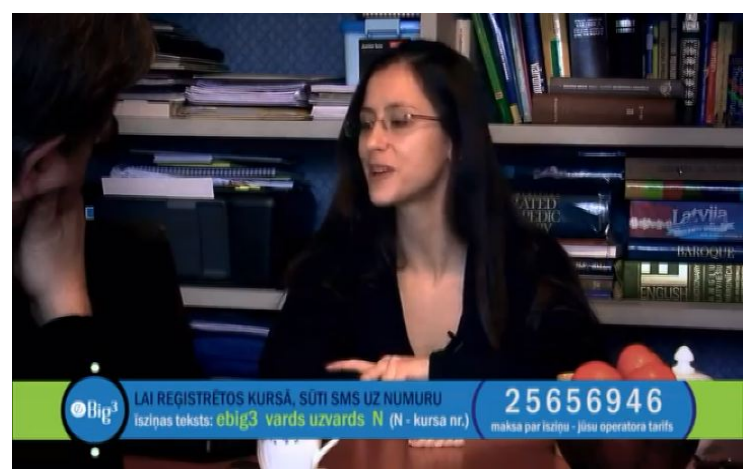

Figure 1: eBig3 course T-component with banner at the bottom of the screen inviting the public to join the course by sending a SMS to: "eBig3, first name, last name and course number".

The procedure to sign-up for the course is simple. A viewer only needs to give his first and last name and course number she is interested in and send this information with an SMS. Signing up for additional courses follows the same procedure.

It is a simpler procedure than completing a user profile in an Internet environment. The response is almost immediate; in about the minute a user receives a login. Our system corrects some typical mistakes, and most registration attempts are successful. In case of an unsuccessful registration, the user receives an error massage and repeats the registration process. Nearly all users successfully register after the second or at the most the third attempt.

Typical problems encountered are users losing logins. The recovery process is simple. The eBig3 system sends an SMS with the password that looks like this: "ebig3 password".

An important application of the m-component is sending learning support. E-learning courses traditionally experience a high drop-out rate; we therefore used the mobile SMS system to send additional messages in certain selected situations to encourage user efforts. We have identified these events as follows:

- Sending a congratulatory message after joining the course;

- Sending friendly reminders to be more active in the course;

- Confirming active participation in a Course Unit;

- Informing about face-to-face seminar sessions and providing the time and place;

- Sending a congratulatory message after course completion;

- Sending information about newly published courses;

- Other important communications about learning events.

The SMS system helps to maintain virtual contact with learners. It strengthens the living contacts that are maintained by seminars and phone contacts.

The SMS messaging system is triggered by the following events:

- Planned event data base;

- Unique actions of users (like registration);

- Users' behaviour analysis and results.

E-content is central to the course material delivery process; it ensures that the content is consistent with the level of the learning objectives and that the volume, assessments, tests etc. are well matched to user learning levels. The e-content is located in the Moodle learning environment. The users' behaviour is registered by mouse click data in each course unit.

\section{3 eBig3 COURSE DELIVERY}

eBig3 course delivery was organised after 
registration. Ninety percent of the registered users entered the course using a login received via a SMS (Figure 2).

The eBig3 courses and seminars were organised at four universities in Latvia: Riga Technical University, Daugavpils University, Liepaja University, and Latvia University of Agriculture.

After the first week of activities a motivational SMS was sent to all participants. The SMS content was selected on the bases of user activities in the course.

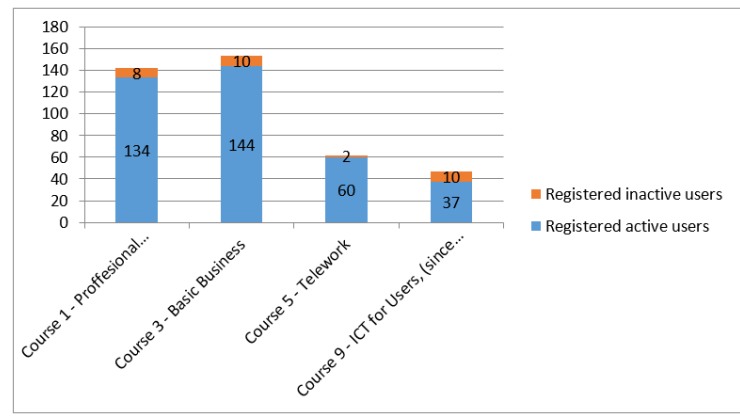

eBig3 Users Registered

in Courses $1,3,5$ and 9 (Week 1-13)

Figure 2: Registered users and users entering the course.

The seminars were organised every week on regular rotating basis at one of the participating universities. The information for the next seminar was sent by SMS to each registered user. These activities maintained the momentum of the on-going learning.

The users completed the tests, exercises and final assessment work; they also communicated with the course teachers.

The users who successfully completed the course with final assignment work received the partner university certificate.

\section{4 ebig3 COURSE PILOTING}

The information on eBig3 courses-- titles, learning objectives, delivery approach-- was published in the www.ebig3.eu portal.

1. Professional Communications (23 Learning Objects (LO))

2. Basic Business (190 LO)

3. Information Society and Telework (82 LO)

4. Computers for Beginners (58 LO)

5. Computers for Users (170 LO)

6. Landscape Architecture and Design (54 LO)

7. Renewable Energy Resources (39 LO)

8. Latvian-Lithuanian Communications (27 LO)

9. 23 things to know for Business Beginners (59
LO)

10. Internet Marketing and Advertising (1 link to course in an external environment)

The most popular courses were:

1. Professional Communications

2. Basic Business

3. Information Society and Telework

4. Computers for Users

5. Landscape Architecture and Design

The course content was uploaded in Moodle except for the Course No 10 that was located in another e-learning environment linked to Moodle.

There were was a 12 minutes long video broadcasted 30 times on Latvian Regional TV. Each course had separate video clip with a banner at the lower end of the screen inviting viewers to join eBig3 courses by sending an SMS. The Project flyers were also distributed in libraries and municipalities in the vicinity of surrounding the partner universities.

The number of participants rapidly increased. Figure 3 shows the number of participants in first eleven days of course delivery

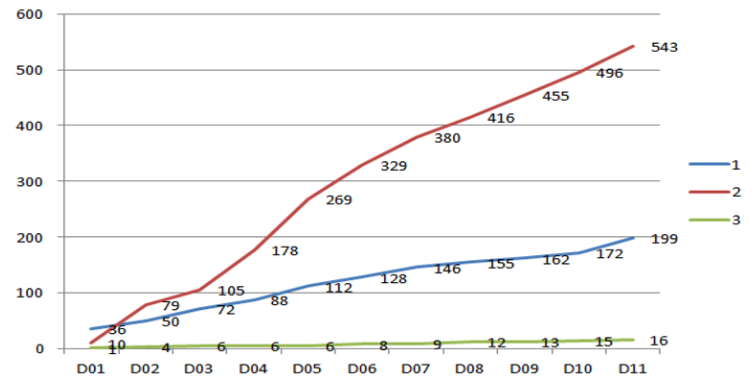

Figure 3.

Figure 3 shows the number of participants in the Latvian speaking area of the first eleven days of course delivery. No. 1 graph eBig3 course registration that is accomplished by sending an SMS giving first and last name as well as course number; No. 2- are public IT courses available in the Riga City portal www.riga.lv. The public was informed about them through large scale advertising, No registration was necessary. No. 3- public business courses advertised on a medium scale; users were required to give profile information online.

Figure 4 shows the increase of eBig3 users during the first 13 weeks of course delivery.

Each course had number of learning objects, from 23 to 190 eBig3 information system collected data by mouse clicks for each course.

We calculated the cumulative ratio of the number 


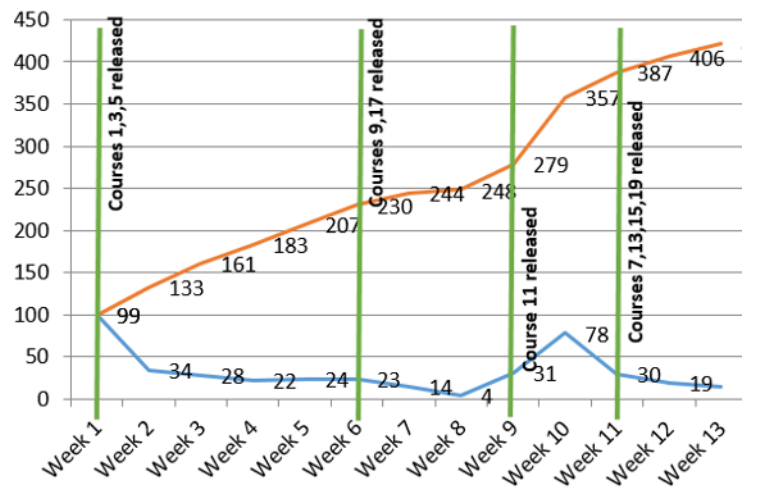

Figure 4: The number of participants in Latvian speaking area in the first 13 weeks of eBig3 course delivery (1); and number of new registrations every week (2).

of average user mouse clicks for each course:

1. Professional Communications $-1,50$

2. Basic Business $-0,48$

3. Information Society and Telework $-0,83$

4. Computers for Users - 0,59

5. Landscape Architecture and Design -1,39

The cumulative ratio is the average ratio of mouse clicks per the number of learning objects for all users who entered to course. The next Figure 5 shows the increase of the cumulative ratio vs. the number of learning objects.

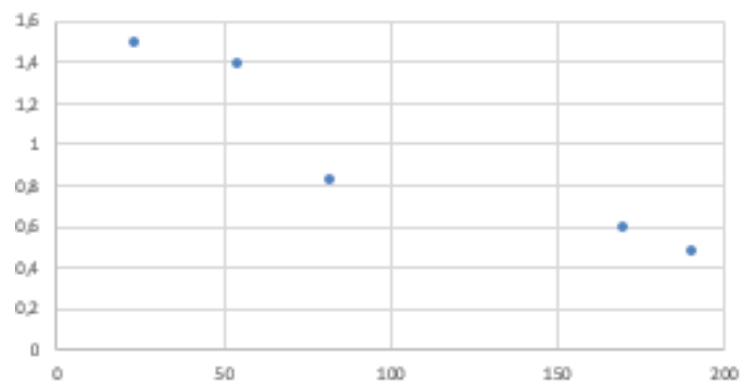

Figure 5: Cumulative ratio (mouse clicks / number of learning objects) vs. the number of learning objects for five of the most popular eBig3 courses.

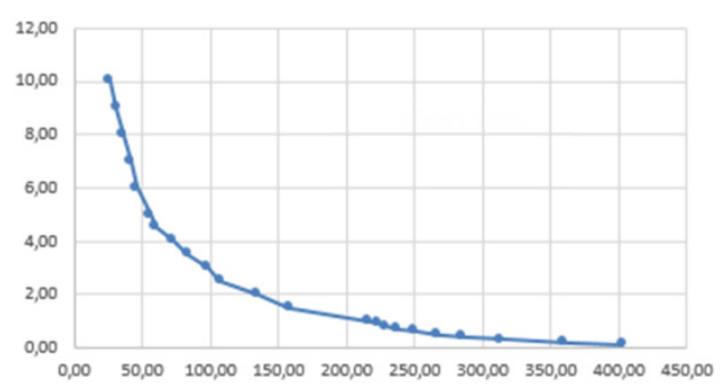

Figure 6: Number of effective volume of eBig3 courses vs. the number of users.
We calculated how many learning objects were clicked by each participant. The next Figure 6 shows that more than 216 participants from 523 used content with volume for more than one eBig3 course. More than 267 participants used content with size for more than 0,5 eBig3 course; and more than 403 participants used content with size for more than 0,1 eBig3 courses.

\section{CONCLUSIONS}

The conclusions are listed below:

1. The registration for e-courses with SMS with the eBig3 approach shows a strong increase of participants compared with the traditional internet registration procedure.

2. Half of the eBig3 learners who joined the course covered at least $50 \%$ of one course content in terms of volume.

3. The triple screen eBig3 approach better met the needs of life-long-learners than traditional single screen based eLearning.

\section{ACKNOWLEDGEMENTS}

This research has been supported by a grant from the European Regional Development Fund (ERFD/ERAF) project "New User behavioural interpretation algorithms to facilitate an efficient transfer of knowledge within an e-ecosystem (JAUZI)", Grant Agreement 2013/0071/2DP/ 2.1.1.1.0/13/APIA/VIAA/023.

\section{REFERENCES}

Byers, K. P. C. (2013). KPCB Internet Trends 2013: Venture Capital at KPCB.

Ducey, R. V., \& Phalen, P. F. (2011). Study of user experience on multiple video screens and formats: Council for Research Excellence.

Google. (2012). The new multi-screen world: Understanding cross-platform consumer behavior. Technical report, from http://www.google.com/think/ research-studies/ the-new- multi-screen- world-study. html.

ITU-D. (2009). The World in 2009: ICT facts and figures. 8. http://www.itu.int/ITU-D/ict/material/Telecom09 flyer.pdf.

ITU-D. (2010). The World in 2010: ICT facts and figures. 8. http://www.itu.int/ITU-D/ict/material/FactsFigures 2010.pdf.

ITU. (2008). Use of information and communication 
technology by the world's children and youth (A statistical compilation). (15.10.2009.), 93. http:// www.itu.int/ITU-D/ict/material/Youth_2008.pdf.

Kapenieks, A., Zuga, B., Stale, G., \& Jirgensons, M. (2012a). An E-Ecosystem Driven Next Generation Life Long Learning Approach. Paper presented at the ISTAfrica 2012 Conference, Daresalama, Tanzania.

Kapenieks, A., Zuga, B., Stale, G., \& Jirgensons, M. (2012b). eEcosystem Driven eLearning vs Technology Driven e-Learning. Paper presented at the 4th International Conference on Computer Supported Education (CSEDU 2012), Portugal, Porto.

Kapenieks, A., Zuga, B., Stale, G., \& Jirgensons, M. (2012c). Internet, Television and Mobile Technologies for Innovative iLearning. Paper presented at the Rezeknes University College Conference "Society, Integration, Education".

Pfeffer, T. (2012). Virtualization of Universities Digital Media and the Organization of Higher Education Institutions. Springer New York Dordrecht Heidelberg London: Springer Science+Business Media.

Turrill, D. (2013). A Look Across Media - The CrossPlatform Report: SVP Insights Nielsen.

Zaller, J. (2013). Largest Ever Study of Broadcast Market Reveals Most Important Industry Trends for 2013. from http://blog.devoncroft.com. 